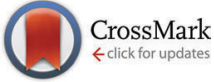

Cite this: Chem. Commun., 2016, 52,6300

Received 8th February 2016 Accepted 1st April 2016

DOI: $10.1039 / c 6 c c 01233 g$

www.rsc.org/chemcomm

\section{Evidence for an intrinsic binding force between dodecaborate dianions and receptors with hydrophobic binding pockets $\dagger$}

\author{
Jonas Warneke, ${ }^{\star a}$ Carsten Jenne, ${ }^{b}$ Johannes Bernarding, ${ }^{c}$ Vladimir A. Azov ${ }^{\star a}$ and \\ Markus Plaumann ${ }^{\star c}$
}

\begin{abstract}
A gas phase binding study revealed strong intrinsic intermolecular interactions between dianionic halogenated closo-dodecaborates $\left[\mathrm{B}_{12} \mathrm{X}_{12}\right]^{2-}$ and several neutral organic receptors. Oxidation of a tetrathiafulvalene host allowed switching between two host-guest binding modes in a supramolecular complex. Complexes of $\beta$-cyclodextrin with $\left[\mathrm{B}_{12} \mathrm{~F}_{12}\right]^{2-}$ show remarkable stability in the gas phase and were successfully tested as carriers for the delivery of boron clusters into cancer cells.
\end{abstract}

Halogenated closo-dodecaborates ${ }^{1}\left(\left[\mathrm{~B}_{12} \mathrm{X}_{12}\right]^{2-}, \mathrm{X}=\mathrm{F}, \mathrm{Cl}, \mathrm{Br}, \mathrm{I}\right.$, Fig. 1) are weakly interacting inorganic dianions with icosahedral molecular symmetry and highly delocalized electron deficient bonding between the cluster boron atoms. It is well documented that dodecaborates behave different in terms of intermolecular interaction in comparison with other "common" anions. The surprisingly weak binding affinity of the closo-dodecaborate dianions with cationic species, which allows classifying them as extremely weak anionic bases, led to new records in superacidity $^{2}$ and allowed the stabilization of highly reactive cations. ${ }^{3}$ On the other hand, the potential for the formation of intermolecular complexes of dodecaborates with molecules that do not usually bind to anions has been so far overlooked.

To the best of our knowledge, the only study on the molecular recognition of anionic closo-dodecaborates with non-charged organic hosts has been published very recently. ${ }^{4}$ It reports very strong binding of $\left[\mathrm{B}_{12} \mathrm{X}_{12}\right]^{2-}(\mathrm{X}=\mathrm{H}, \mathrm{Cl}, \mathrm{Br}, \mathrm{I})$ with cyclodextrins $(\mathrm{CDs})^{5}$ in aqueous solutions. ${ }^{6,7}$ This binding of the dianions to the unpolar cyclodextrin pockets was rationalized by the

\footnotetext{
${ }^{a}$ Universität Bremen, Institut für Angewandte und Physikalische Chemie, Leobener Str. NW 2, D-28334 Bremen, Germany. E-mail: jonas.warneke@uni-bremen.de, vazov@uni-bremen.de

${ }^{b}$ Bergische Universität Wuppertal, Fakultät für Mathematik und

Naturwissenschaften, Gaussstrasse 20, D-42119 Wuppertal, Germany

${ }^{c}$ Otto-von-Guericke Universität Magdeburg, Institut für Biometrie und Medizinische Informatik, Leipziger Str. 44, D-39120 Magdeburg, Germany.

E-mail: markus.plaumann@med.ovgu.de

† Electronic supplementary information (ESI) available: Analytical procedures, additional mass-spectra, and cell cultures. See DOI: 10.1039/c6cc01233g
}
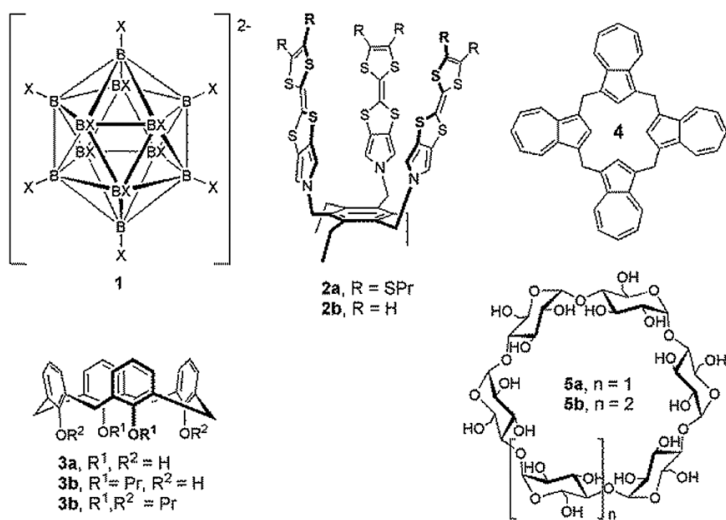

$2 a, R=S P r$
$2 b, R=H$

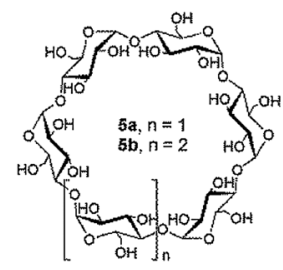

Fig. 1 Structures of $\left[B_{12} X_{12}\right]^{2-}$ clusters (1a: $X=F, \mathbf{1 b}: X=C l, 1 \mathbf{c}: X=B r$, 1d: $X=I$ ) and molecular hosts 2-5.

chaotropic effect, ${ }^{8}$ which can be explained as follows: the relocation of strongly chaotropic (i.e. disrupting the hydrogen bonding network of water molecules) dodecaborate anions from the aqueous medium into hydrophobic binding pockets allows for the recovery of the water structure distorted by the chaotropes. Due to the very pronounced chaotropic features of the dodecaborates they were thus classified as "superchaotropes" that lie far beyond the canonical Hoffmeister scale ${ }^{9}$ for anions. Although direct attractive interactions of dodecaborates with neutral $\mathrm{CD}$ hosts were implied by the authors as a possible additional driving force for the complexation, ${ }^{4}$ they could not be directly verified in a solution.

Investigations of the host-guest chemistry of neutral molecules with dodecaborate anions are of fundamental importance for understanding the intrinsic nature of weak intermolecular interactions. They are also of high relevance for possible practical applications of boron clusters, ${ }^{10}$ among which boron neutron capture therapy (BNCT) of cancer ${ }^{11}$ is the most prominent one. Thus, in an independent simultaneously performed study, we investigated inclusion complexes between different types of molecular hosts with hydrophobic binding pockets and dodecaborates in the gas phase, where possible solvent effects 
are excluded..$^{12}$ It should be noted that a doubly charged guest must be non-basic to ensure complex stability in the gas phase. Typical basic dianions would be immediately protonated by any acidic proton present in a host (such as HO-groups in cyclodextrins), leading to complex dissociation due to Coulomb repulsion. Therefore, suitable dianions must exhibit extremely weak gas phase basicity - a property strongly correlating with the thermodynamic stability of double negatively charged anions in the gas phase. ${ }^{2,13}$ Similar to dodecaborates, ${ }^{14}$ multiply negatively charged polyoxometallate (POM) clusters are also stable in the gas phase. ${ }^{15}$ Therefore, a recent report on the unexpected complexation of POMs by cyclodextrins served as an additional motivation for our study. ${ }^{16}$

Molecular hosts 2-5 (Fig. 1) were tested for their binding affinity to halogenated dodecaborates. Tetrathiafulvalene (TTF) containing compounds 2 and similar hosts containing two or more TTF units comprising an electron-rich binding pocket are known to bind electron deficient aromatic guests, such as tetracyanoquinodimethane, ${ }^{17}$ nitroaromatic derivatives, ${ }^{18,19}$ fullerenes, ${ }^{18,20}$ or charged pyridinium derivatives. ${ }^{12}$ Calix[4]arenebased $^{21}$ hosts 3 are complementary in size and their complexes with spherical hosts like fullerenes have been observed in crystal structures. Due to a large dipole moment of the azulene moiety, calix[4]azulenes ${ }^{22} 4$ in the cone conformation have a strong permanent dipole moment with the positive side directed to the binding pocket, which was expected to stabilize a potential complex with $\left[\mathrm{B}_{12} \mathrm{X}_{12}\right]^{2-}$. Cyclodextrins 5 are hydrophilic molecules well-known for the binding of neutral lipophilic compounds in their unpolar binding pockets.

For binding experiments, the host molecules were dissolved together with dodecaborate samples 1 (for exact experimental details see the ESI $\dagger$ ) and the solutions were injected via a syringe pump into an electrospray source. The ionic species formed in the gas phase were analyzed by ion trap mass spectrometry. In all runs, the mass range up to $m / z 2000$ was scanned to detect possible multicomponent host-guest aggregates with high molecular masses.

Surprisingly, tests with the lipophilic tripodal TTF-containing molecular host ${ }^{23} 2$ gave immediate evidence for the formation of intermolecular complexes with $1 \mathbf{1 a}^{24}$ As an example, Fig. 2a shows the mass spectrum obtained from a solution containing $\left[\mathrm{B}_{12} \mathrm{~F}_{12}\right]^{2-}$ and molecular host 2a. Singly negatively charged ionic clusters comprising $\left[\mathrm{B}_{12} \mathrm{~F}_{12}\right]^{2-}$ and different counter ions, such as tetraalkylammonium and alkali metal cations, were observed between $\mathrm{m} / \mathrm{z} 800$ and 900 . The formation of these aggregates during the electrospray process is well known and explained by interionic Coulomb attraction. However, a doubly charged ion observed at $\mathrm{m} / \mathrm{z} 643$ indicated the formation of the $1: 1$ supramolecular complex $\left[\left[\mathrm{B}_{12} \mathrm{~F}_{12}\right] \cdot 2 \mathrm{a}\right]^{2-}$ of the negatively-charged dodecaborate with the neutral tetrathiafulvalene host.

Collision induced dissociation (CID) of the host-guest complexes required excitation energies close to those typically needed to dissociate covalent bonds in organic analytes. Usually, the formation of aggregates of molecular ions with neutral molecules is observed very rarely under the applied ionization conditions (see the ESI $\dagger$ ), and therefore, their formation serves as a clear indication of strong

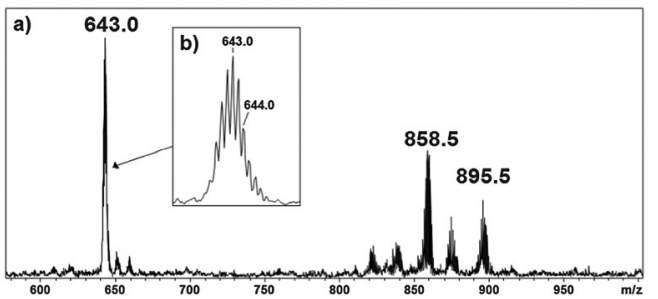

Fig. 2 (-)-ESI-MS spectra measured for a solution of $\left[\mathrm{HN}\left(\mathrm{CH}_{3}\right)_{3}\right]_{2}\left[\mathrm{~B}_{12} \mathrm{~F}_{12}\right]+$ 2a in $\mathrm{CH}_{2} \mathrm{Cl}_{2} / \mathrm{CH}_{3} \mathrm{CN}(1: 2)$. (a) Overview spectrum showing molecular aggregates. Detected signals between $\mathrm{m} / \mathrm{z} 800$ and $\mathrm{m} / \mathrm{z} 900$ are assigned to $\left[(\mathrm{Cat})_{3}\left(\mathrm{~B}_{12} \mathrm{~F}_{12}\right)_{2}\right]^{-}$with $\mathrm{Cat}=\left[\mathrm{HN}\left(\mathrm{CH}_{3}\right)_{3}\right]^{+}, \mathrm{Na}^{+}, \mathrm{K}^{+}$in various combinations. (b) The inset displays the isotopic pattern of the detected host-guest complex $\left[\left[\mathrm{B}_{12} \mathrm{~F}_{12}\right] \cdot 2 \mathrm{a}\right]^{2-}$

direct interactions between the dodecaborate dianion and the neutral TTF-containing molecular host. The binding of this dianionic guest by this neutral molecule represents a so far unprecedented instance.

Although we can only speculate about the molecular structure of this supramolecular complex, size complementarity of the guest with the binding pocket of the host implies the formation of an inclusion type complex. Doubly charged aggregates containing two host molecules $\left(\left[\left(\mathrm{B}_{12} \mathrm{Cl}_{12}\right) \cdot(\mathbf{2 a})_{2}\right]^{2-}\right)$ were also detected in the MS spectra (Fig. 3c). The likely structure of this complex is a spherical dodecaborate anion capped by two oppositely faced host molecules (Fig. 3a).

TTF derivatives are known in the context of their application as redox-controllable molecular switches. ${ }^{25}$ Oxidation of TTFbased hosts leads to a positively charged electron-deficient state incapable of binding electron-deficient neutral or cationic guest molecules. On the other hand, the oxidized state of the hosts should show an affinity to negatively-charged species, which are usually not bound in the neutral state of this host, due to Coulomb attraction. In order to detect the Coulombstabilized complex of $\mathbf{2 a}$, we converted two of three TTF units into the radical-cationic state and thus rendering double
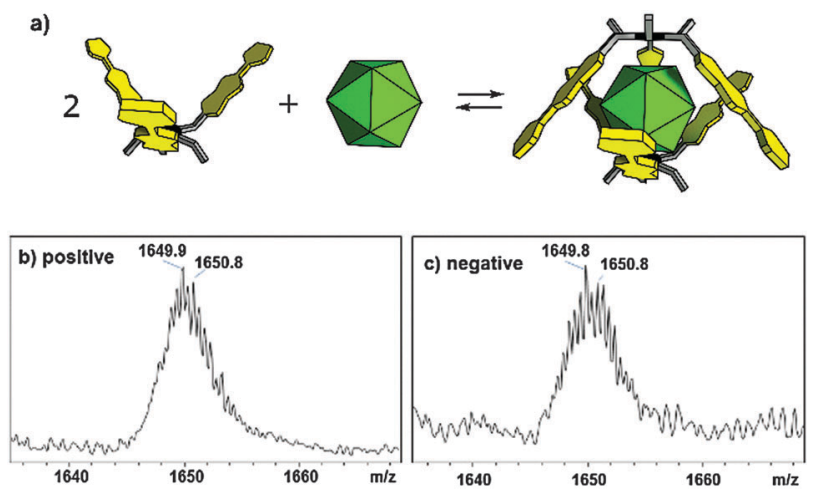

Fig. 3 (a) Schematic illustration of complex formation between host $\mathbf{2 a}$ (yellow) and $\left(\mathrm{B}_{12} \mathrm{Cl}_{12}\right)^{2-}$ (green icosahedron) showing the plausible doubledecker structure of $\left[\left(\mathrm{B}_{12} \mathrm{Cl}_{12}\right) \cdot(\mathbf{2 a})_{2}\right]$. Depending on the oxidation state of $\mathbf{2 a}$ (neutral or double positively charged), the overall charge of the complex can be either $2-$ or $2+$; (b) signal shape of $\left[\left(\mathrm{B}_{12} \mathrm{Cl}_{12}\right) \cdot(2 \mathrm{a})_{2}\right]^{2+}$ as a doubly positively charged ion after the oxidation of TTF units; (c) signal shape of $\left[\left(\mathrm{B}_{12} \mathrm{Cl}_{12}\right) \cdot(\mathbf{2} \mathbf{a})_{2}\right]^{2-}$ as a doubly negatively charged ion. 
positive charge for the whole host molecule by oxidation with approximately 2 eq. of $[\mathrm{NO}]^{+}\left[\mathrm{SbF}_{6}\right]^{-}$in $\mathrm{MeCN} / \mathrm{CH}_{2} \mathrm{Cl}_{2}(1: 2)$ solution. Two-fold oxidation of $2 \mathrm{a}$ was confirmed by ESI-MS measured in the positive mode. After addition of $\left[\mathrm{B}_{12} \mathrm{Cl}_{12}\right]^{2-}$ to $2 \mathrm{a}^{2+}$, ESI-MS proved the formation of the positively-charged $\left[\left(\mathrm{B}_{12} \mathrm{Cl}_{12}\right) \cdot(2 \mathrm{a})_{2}\right]^{2+}$ complex (Fig. 3b). Thus, in this unique hostguest system, the oxidation state of the supramolecular complex can be switched from -2 to +2 parallel to the change of the type of intermolecular interactions between the two components of the complex.

ESI-MS of mixed solutions of $\mathbf{1 a - d}$ with hosts $\mathbf{3 a - c}$ and $\mathbf{4}$ did not result in the detection of any complexes in the gas phase, only free dodecaborate anions and their aggregates with positively charged counterions were observed in the negative mode, and molecular ions or aggregates of the host molecules were observed in the positive mode. ${ }^{26}$ This clearly shows that the binding of dodecaborates is a selective process that cannot be explained by their general affinity to any lipophilic cavity.

MS binding experiments with $\alpha$ - and $\beta$-cyclodextrins (CDs) $\mathbf{5 a}, \mathbf{b}$ showed that $\mathbf{1 a}, \mathbf{b}$ displayed strong affinity to this receptor class also in the gas phase (see ESI $\dagger$ ). Initially we performed competition binding experiments of different $\left[\mathrm{B}_{12} \mathrm{X}_{12}\right]^{2-}(\mathrm{X}=\mathrm{F}$, $\mathrm{Cl}, \mathrm{Br}, \mathrm{I})$ anions with $\mathbf{5 a}, \mathbf{b}$ from $\mathrm{MeOH}$ solution using $\mathrm{MS}$ and established that the fluorinated dodecaborate 1a binds strongest to both CDs. These complexes are very stable in the gas phase, as was proved by CID experiments. Surprisingly, the fragmentation of the $\beta$-CD complex $\left[\left(\mathrm{B}_{12} \mathrm{~F}_{12}\right) \cdot \mathbf{5 b}\right]^{2-}$ led to the loss of one glucose unit $\left(\mathrm{C}_{6} \mathrm{H}_{10} \mathrm{O}_{5}\right.$, a molecular mass of $\left.162 \mathrm{Da}\right)$ (Fig. 4) as a competing reaction to complex dissociation. An equivalent reaction was not observed for any other complex containing $\mathbf{5 a}$ or $\mathbf{5 b}$. The preferred binding of $\left[\mathrm{B}_{12} \mathrm{~F}_{12}\right]^{2-}$ to $\mathbf{5 b}$ instead of $\mathbf{5 a}$ was also demonstrated by the dissociation of the $\left[\mathbf{5 a} \cdot\left(\mathrm{B}_{12} \mathrm{~F}_{12}\right) \cdot \mathbf{5 b}\right]^{2-}$ complex that led exclusively to the formation of $\left[\left(\mathrm{B}_{12} \mathrm{~F}_{12}\right) \cdot \mathbf{5 b}\right]^{2-}$ (see ESI $\dagger$ ). No gas phase complex formation was observed between cyclodextrin hosts and other strongly chaotropic anions, such as $\left[\mathrm{ClO}_{4}\right]^{-}$ and $\left[\mathrm{PF}_{6}\right]^{-}$.

The apparent driving force for the self-assembly of halogenated dodecaborates with host molecules is strong dispersion interactions. Size complementarity with the binding pockets of their hosts allows dispersion forces to add up over large contact surfaces. The binding of $1 \mathrm{a}$ with the electron rich host 2 can be rationalized by the very unusual chemical nature of dodecaborate anions. While "common" anions are mostly highly nucleophilic, which leads to their repulsion by electron rich hosts, dodecaborates and their derivatives are the least coordinating dianions described

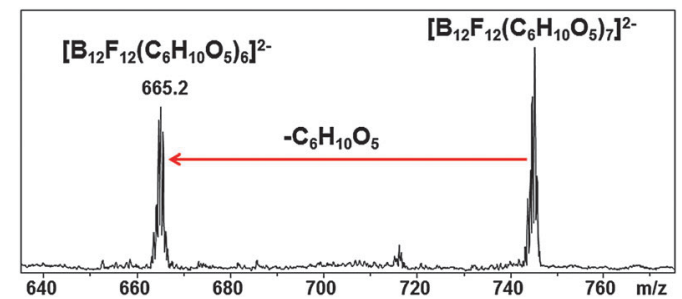

Fig. 4 (-)-ESI-MS spectra of the $\left[\left(\mathrm{B}_{12} \mathrm{~F}_{12}\right) \cdot 5 \mathbf{b}\right]^{2-}$ complex after isolation and excitation. The spectrum shows the loss of one glucose unit. so far. The double negative charge in $\left[\mathrm{B}_{12} \mathrm{X}_{12}\right]^{2-}$ is delocalized over the extended guest framework, minimizing its repulsion from the electron rich host.

The binding affinity of $\mathbf{1 a}$ to $\mathbf{5 a}$ and $\mathbf{5 b}$ in aqueous solution was also determined by means of NMR binding titrations using the ${ }^{19} \mathrm{~F}$ chemical shift of the fluorine atoms of the guest for fitting of the binding data (see ESI $\dagger$ ). Similar to the gas phase, $\beta$-cyclodextrin $\mathbf{5 b}$ proved to be a much stronger binder to $\left[\mathrm{B}_{12} \mathrm{~F}_{12}\right]^{2-}$ than cyclodextrin $5 \mathrm{a}\left(K_{\mathrm{a}}=260\right.$ and $6 \mathrm{M}^{-1}$, respectively). The evidence of high intrinsic affinity between $\mathbf{1 a}$ and $\mathbf{5 b}$ and the possibility of the simple detection of $\mathbf{1 a}$ in complex organic mixtures using ${ }^{19} \mathrm{~F}$ NMR spectroscopy served as a motivation for experiments with biological systems. Thus, we tested the influence of $\beta$-CD $\mathbf{5 b}$, the most easily accessible member of the cyclodextrin family, on the cellular uptake of $\left[\mathrm{B}_{12} \mathrm{~F}_{12}\right]^{2-}$ dianions. We used two fast growing cell lines, fibroblast L929 and human malignant melanoma RPMI-7951, to demonstrate that the hydrophilic $\left[\mathrm{B}_{12} \mathrm{~F}_{12}\right]^{2-}$ anion, which has a very limited possibility for penetration through the lipophilic cell membrane, could be transferred into cells upon its complexation with $\mathbf{5 b}$.

Cells were incubated for 22 hours in a $1.2 \mathrm{mM}$ solution of $\left[\mathrm{B}_{12} \mathrm{~F}_{12}\right]^{2-}$ with or without the presence of $\beta$-CD $5 \mathbf{b}$ at the concentration of $1.4 \mathrm{mM}$. After the incubation, the cells were carefully washed (see ESI $\dagger$ ) and filled into $5 \mathrm{~mm}$ NMR tubes for ${ }^{19} \mathrm{~F}$ NMR measurements. The ${ }^{19} \mathrm{~F}$ NMR spectra of the washed cells incubated with the $\left[\left(\mathrm{B}_{12} \mathrm{~F}_{12}\right)^{2-} \cdot \mathbf{5 b}\right]$ complex in the cell culture medium showed a signal of $\left[\mathrm{B}_{12} \mathrm{~F}_{12}\right]^{2-}$ anions (Fig. 5), whereas the incubation of cells with $\mathrm{Na}_{2}\left[\mathrm{~B}_{12} \mathrm{~F}_{12}\right]$ in the absence of $\beta$-CD did not lead to any uptake of the boron clusters. In the latter case, the whole amount of the fluorinated compound completely remained in the incubation medium, as was proved by concentration-calibrated ${ }^{19} \mathrm{~F}$ NMR spectra.

Toxicity tests (see the ESI $\dagger$ for details) evidenced that the incubation of both cell lines with $\beta$-CD $5 \mathbf{b}, \mathrm{Na}_{2}\left[\mathrm{~B}_{12} \mathrm{~F}_{12}\right]$, and $\left[\left(\mathrm{B}_{12} \mathrm{~F}_{12}\right)^{2-} \cdot \mathbf{5 b}\right]$ complex solutions for prolonged time periods did not affect their growth rate or morphology. Since specific derivatization of cyclodextrins can improve their selective

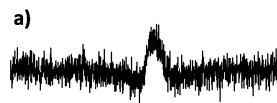

b)

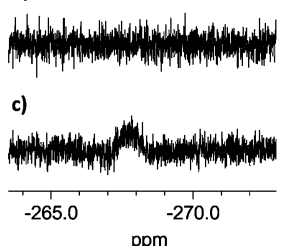

d)

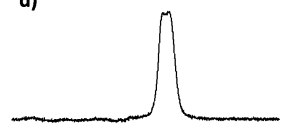

e)

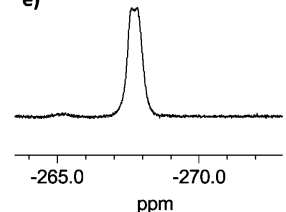

Fig. $5{ }^{19} \mathrm{~F}$ NMR spectra (282.4 MHz) of: (a) incubation medium (DMEM) containing $1 \mathrm{mM}$ of $\mathrm{Na}_{2}\left[\mathrm{~B}_{12} \mathrm{~F}_{12}\right]$, (b) unlabeled fibroblasts $L 929$ (the unsuccessful cell labeling experiment with uncomplexed $\left.\mathrm{Na}_{2}\left[\mathrm{~B}_{12} \mathrm{~F}_{12}\right]\right)$, (c) labeled fibroblasts L929 (the cell labeling experiment using the $\left[\left(\mathrm{B}_{12} \mathrm{~F}_{12}\right)^{2-} \cdot 5 \mathrm{~b}\right]$ complex), (d) $\mathrm{Na}_{2}\left[\mathrm{~B}_{12} \mathrm{~F}_{12}\right]$ in $\mathrm{D}_{2} \mathrm{O}$ at $313 \mathrm{~K}$ and (e) $\beta$-CD. $\left[\mathrm{B}_{12} \mathrm{~F}_{12}\right]^{2-}$ complex in $\mathrm{D}_{2} \mathrm{O}$ at $313 \mathrm{~K}$. Spectra (a)-(c) were recorded using an external $\mathrm{D}_{2} \mathrm{O}$ lock and $\mathrm{ns}=128, d_{1}=20 \mathrm{~s}$. Spectra (d) and (e) were detected using a concentration of $8.75 \mathrm{mM}\left(\mathrm{Na}_{2}\left[\mathrm{~B}_{12} \mathrm{~F}_{12}\right]\right)$ and $\mathrm{ns}=16$ and $d_{1}=10 \mathrm{~s}$. 
affinity to tumor cells ${ }^{27,28}$ and dodecaborates are less expensive to prepare than analogous carborans, the use of CD complexes with dodecaborates opens new possibilities for advances in BNCT methodology.

To summarize, we have investigated the binding of anionic spherical shaped dodecaborates to several organic non-polar host molecules in the gas phase and discovered a significant intrinsic binding affinity between these seemingly noncomplementary molecules. Dodecaborates displayed selectivity for the large hosts with deep hydrophobic polarizable pockets, as in the case of TTF-based receptors, or spherical cavities of complementary shape, as with cyclodextrins. Our report complements in a timely manner the recent study of CD-dodecaborate complexes in solution ${ }^{4}$ and goes in line with the arising interest for the construction and investigation of non-charged organic macrocyclic receptors for "conventional",29 and "non-conventional",16 anions. Besides, we have devised a supramolecular system that can be switched between two binding modes based on different types of interactions upon oxidation of one of the components and demonstrated that CD complexes of dodecaborates can be employed for the translocation of boron clusters into living cells.

We are grateful to Prof. P. Georghiou (Memorial University of Newfoundland, Canada) for samples of $\mathbf{4}$, to Dr T. Duedal (DB Lab, Denmark) and Dr S. Bahring (University of Southern Denmark) for their help with 3D graphics, to M. Rohdenburg (University of Bremen) for some theoretical calculations in context of this work, as well as S. Ribal and D. Lego (University of Magdeburg) for assistance with cell culture experiments.

\section{Notes and references}

1 C. Knapp, Weakly Coordinating Anions: Halogenated Borates and Dodecaborates, in Comprehensive Inorganic Chemistry II, ed. J. Reedijk and K. Poeppelmeier, Elsevier, Oxford, 2013, vol. 1, pp. 651-679.

2 (a) A. Avelar, F. S. Tham and C. A. Reed, Angew. Chem., Int. Ed., 2009, 48, 3491-3493; (b) C. Jenne, M. Keßler and J. Warneke, Chem. - Eur. J., 2015, 21, 5887-5891.

3 (a) C. Knapp and C. Schulz, Chem. Commun., 2009, 4991-4993; (b) C. Bolli, J. Derendorf, M. Keßler, C. Knapp, H. Scherer, C. Schulz and J. Warneke, Angew. Chem., Int. Ed., 2010, 49, 3536-3538; (c) M. Kessler, C. Knapp and A. Zogaj, Organometallics, 2011, 30, 3786-3792.

4 K. I. Assaf, M. S. Ural, F. Pan, T. Georgiev, S. Simova, K. Rissanen, D. Gabel and W. M. Nau, Angew. Chem., Int. Ed., 2015, 54, 6852-6856. 5 F. Hapiot, S. Tilloy and E. Monflier, Chem. Rev., 2006, 106, 767-781. 6 In contrast to charged dodecaborates, there are many reports on complexes of neutral carboranes with neutral organic guests, see for example: (a) R. J. Blanch, M. Williams, G. D. Fallon, M. G. Gardiner, R. Kaddour and C. L. Raston, Angew. Chem., Int. Ed. Engl., 1997, 36, 504-506; (b) M. J. Hardie and C. L. Raston, Eur. J. Inorg. Chem., 1999, 195-200; (c) R. J. Blanch, A. J. Sleeman, T. J. White, A. P. Arnold and A. I. Day, Nano Lett., 2002, 2, 147-149; (d) R. Vaitkus and S. Sjöberg, J. Inclusion Phenom. Macrocyclic Chem., 2011, 69, 393-395.
7 For a recent review on molecular recognition in water, see: E. A. Kataev and C. Müller, Tetrahedron, 2014, 70, 137-167.

8 (a) P. Ball and J. E. Hallsworth, Phys. Chem. Chem. Phys., 2015, 17, 8297-8305; (b) Y. Marcus, Chem. Rev., 2009, 109, 1346-1370.

9 P. Lo Nostro and B. W. Ninham, Chem. Rev., 2012, 112, 2286-2322.

10 J. Plešek, Chem. Rev., 1992, 92, 269-278.

11 A. H. Soloway, W. Tjarks, B. A. Barnum, F. G. Rong, R. F. Barth, I. M. Codogni and J. G. Wilson, Chem. Rev., 1998, 98, 1515-1562.

12 For reviews on the use of mass-spectrometry for studies of noncovalent interactions, see: (a) D. P. Weimann, M. Kogej and C. A. Schalley, Mass spectrometry and gas phase chemistry of supramolecules, in Analytical Methods in Supramolecular Chemistry, ed. C. A. Schalley, Wiley-VCH, Weinheim, 2nd edn, 2012, vol. 1, pp. 129-196; (b) B. Baytekin, H. T. Baytekin and C. A. Schalley, Org. Biomol. Chem., 2006, 4, 2825-2841.

13 For a review on multiply charged anions in the gas phase, see: A. Dreuw and L. S. Cederbaum, Chem. Rev., 2002, 102, 181-200.

14 J. Warneke, T. Dülcks, C. Knapp and D. Gabel, Phys. Chem. Chem. Phys., 2011, 13, 5712-5721.

15 (a) M. J. Deery, O. W. Howarth and K. R. Jennings, J. Chem. Soc., Dalton Trans., 1997, 4783-4788; (b) K. D. D. Gunaratne, V. Prabhakaran, G. E. Johnson and J. Laskin, J. Am. Soc. Mass Spectrom., 2015, 26, 1027-1035.

16 Y. Wu, R. Shi, Y.-L. Wu, J. M. Holcroft, Z. Liu, M. Frasconi, M. R. Wasielewski, H. Li and J. F. Stoddart, J. Am. Chem. Soc., 2015, 137, 4111-4118.

17 (a) M. H. Düker, H. Schäfer, M. Zeller and V. A. Azov, J. Org. Chem., 2013, 78, 4905-4912; (b) K. R. Korsching, H. Schäfer, J. Schönborn, A. Nimthong-Roldán, M. Zeller and V. A. Azov, RSC Adv., 2015, 5, 82633-82637.

18 K. A. Nielsen, G. H. Sarova, L. Martín-Gomis, F. Fernández-Lázaro, P. C. Stein, L. Sanguinet, E. Levillain, J. L. Sessler, D. M. Guldi, Á. SastreSantos and J. O. Jeppesen, J. Am. Chem. Soc., 2008, 130, 460-462.

19 J. S. Park, F. Le Derf, C. M. Bejger, V. M. Lynch, J. L. Sessler, K. A. Nielsen, C. Johnsen and J. O. Jeppesen, Chem. - Eur. J., 2010, 16, 848-854.

20 S. Fukuzumi, K. Ohkubo, Y. Kawashima, D. Sub Kim, J. Su Park, A. Jana, V. M. Lynch, D. Kim and J. L. Sessler, J. Am. Chem. Soc., 2011, 133, 15938-15941.

21 C. D. Gutsche, Calixarenes. An Introduction, RSC, Cambridge, 2nd edn, 2008.

22 (a) T. D. Lash, J. A. El-Beck and D. A. Colby, J. Org. Chem., 2009, 74, 8830-8833; (b) S. Rahman, A. Zein, L. N. Dawe, G. Shamov, P. Thordarson and P. E. Georghiou, RSC Adv., 2015, 5, 54848-54852.

23 M.-L. L. Watat, T. Dülcks, D. Kemken and V. A. Azov, Tetrahedron Lett., 2014, 55, 741-744.

24 Comparative NMR titration was not possible due to different solubility profiles of $\mathbf{1}$ and $\mathbf{2}$.

25 D. Canevet, M. Sallé, G. Zhang, D. Zhang and D. Zhu, Chem. Commun., 2009, 2245-2269.

26 Not permanently charged host species $\mathrm{M}$ are usually detected as $[\mathrm{M}+\mathrm{H}]^{+},[\mathrm{M}+\mathrm{Na}]^{+},[\mathrm{M}+\mathrm{K}]^{+}$, or $[\mathrm{M}+\mathrm{Cs}]^{+}$In the case of host 4 the quasi molecular ion was detected as $[\mathrm{M}-\mathrm{H}]^{+}$due to the formation of dipyrromethene moieties inside the calix[4]azulene macrocycles; see: T. D. Lash, J. A. El-Beck and D. A. Colby, J. Org. Chem., 2009, 74, 8830-8833.

27 (a) K. Uekama, F. Hirayama and T. Irie, Chem. Rev., 1998, 98, 2045-2076; (b) A. Vyas, S. Saraf and S. Saraf, J. Inclusion Phenom. Macrocyclic Chem., 2008, 62, 23-42.

28 M. E. Davis, Mol. Pharmaceutics, 2009, 6, 659-668.

29 (a) M. Lisbjerg, B. E. Nielsen, B. O. Milhøj, S. P. A. Sauer and M. Pittelkow, Org. Biomol. Chem., 2015, 13, 369-373; (b) M. A. Yawer, V. Havel and V. Sindelar, Angew. Chem., Int. Ed., 2015, 54, 276-279; (c) L. A. Godínez, B. G. Schulze-fiehn, S. Patel, C. M. Criss, J. D. Evanseck and A. E. Kaifer, Supramol. Chem., 1996, 8, 17-22. 